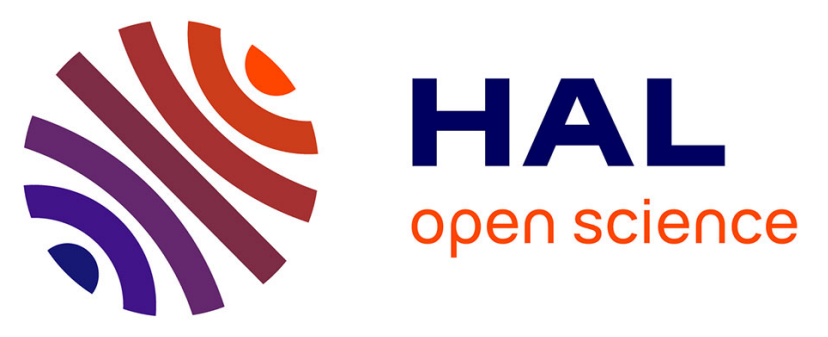

\title{
- mRNA expression in human breast cancer: a meta-analysis
}

Anthony Gonçalves, Pascal Finetti, Renaud Sabatier, Marine Gilabert, José

Adelaïde, Jean-Paul Borg, Max Chaffanet, Patrice Viens, Daniel Birnbaum, François Bertucci

\section{To cite this version:}

Anthony Gonçalves, Pascal Finetti, Renaud Sabatier, Marine Gilabert, José Adelaïde, et al.. - mRNA expression in human breast cancer: a meta-analysis. Breast Cancer Research and Treatment, 2010, 127 (1), pp.273-281. 10.1007/s10549-010-1199-y · hal-00594471

\section{HAL Id: hal-00594471 \\ https://hal.science/hal-00594471}

Submitted on 20 May 2011

HAL is a multi-disciplinary open access archive for the deposit and dissemination of scientific research documents, whether they are published or not. The documents may come from teaching and research institutions in France or abroad, or from public or private research centers.
L'archive ouverte pluridisciplinaire HAL, est destinée au dépôt et à la diffusion de documents scientifiques de niveau recherche, publiés ou non, émanant des établissements d'enseignement et de recherche français ou étrangers, des laboratoires publics ou privés. 


\title{
Brief Report
}

Poly (ADP-ribose) polymerase-1 mRNA expression in human breast cancer: a meta-analysis

\author{
Anthony GONÇALVES ${ }^{1,2,4}$, Pascal FINETTI ${ }^{3}$, Renaud SABATIER ${ }^{1,3}$, \\ Marine GILABERT ${ }^{1,2}$, José ADELAIDE ${ }^{3}$, Jean-Paul BORG ${ }^{2,4}$, Max CHAFFANET ${ }^{3}$, \\ Patrice VIENS ${ }^{1,4}$, Daniel BIRNBAUM ${ }^{3}$, François BERTUCCI ${ }^{1,3,4}$
}

\section{Affiliations of authors:}

'Département d'Oncologie Médicale and U891 INSERM, Centre de Recherche en Cancérologie de Marseille, Institut Paoli-Calmettes Marseille, France

${ }^{2}$ Département de Pharmacologie Moléculaire and U891 INSERM, Centre de Recherche en Cancérologie de Marseille, Institut Paoli-Calmettes Marseille, France ${ }^{3}$ Département d'Oncologie Moléculaire and U891 INSERM, Centre de Recherche en Cancérologie de Marseille, Institut Paoli-Calmettes Marseille, France

${ }^{4}$ Université de la Méditerranée, Marseille, France

Correspondence to: Dr. Anthony GONÇALVES, MD, PhD, Département d'Oncologie Médicale, Institut Paoli-Calmettes, 232 Bd. Ste-Marguerite, 13009 Marseille, France (e-mail:goncalvesa@marseille.fnclcc.fr; Phone : +33 4912235 37 ; Fax : +33 491223670 )

Keywords: PARP1, breast cancer, triple-negative, basal, microarrays 
Abbreviations: PARP1, Poly(ADP-ribose) polymerase-1; SSBs, single-strand breaks; DSBs, double-strand breaks; TN, triple-negative; NB, normal breast; SSP, single sample predictor; DWD, distance weighted discrimination; aCGH, arraycomparative genomic hybridization; MFS, metastasis-free survival; IHC, immunohistochemical; ER, estrogen receptor; PR, progesterone receptor. 


\section{Abstract}

Introduction. Although poly(ADP-ribose) polymerase-1 (PARP1) inhibition is a recent promising therapy in breast cancer, PARP1 expression in this disease is not known.

Methods. Using DNA microarray and array-based comparative genomic hybridization (arrayCGH), we examined PARP1 mRNA expression and copy number alterations in 326 invasive breast cancer samples and normal breast samples. A meta-analysis was performed on a large public retrospective gene expression dataset $(n=2,485)$ to analyze correlation between PARP1 mRNA expression and molecular subtypes and clinico-pathological parameters.

Results. PARP1 was overexpressed in $58 \%$ of cancers, and its expression was heterogeneous between tumors. ArrayCGH data revealed an association between mRNA overexpression and gain/amplification at the PARP1 locus $(p<1.0 \mathrm{E}$ 8). Meta-analysis showed that PARP1 expression was higher in basal breast cancers ( $p<1.0 \mathrm{E}-72)$, but overexpression was also found in other subtypes. PARP1 expression correlated with high grade, medullary histological type, tumor size and worse metastasis-free survival (MFS; $H R=1.12$ [1.04-1.22], $p=0.004$ ) and overall survival $(\mathrm{HR}=1.16$ [1.04-1.29], $p=0.006)$. In multivariate analysis, PARP1 expression had an independent prognostic value for MFS, which was restricted to patients untreated with any adjuvant chemotherapy.

Conclusion. These data demonstrate overexpression of PARP1 in a large number of breast cancers and support the development of PARP inhibitors in basal subtype but also potentially in other breast cancer subtypes. 


\section{Introduction}

Poly(ADP-ribose) polymerase-1 (PARP1), the most abundant member of the PARP superfamily, is a nuclear chromatin-associated protein involved in a wide range of biological processes including cell proliferation, apoptosis, malignant transformation, transcriptional regulation and DNA repair. PARP1 is essential to the base excision repair of DNA single-strand breaks (SSBs) [1]. In response to DNA damage, PARP1 senses and binds to DNA nicks and breaks, resulting in activation of catalytic activity, causing poly(ADP)ribosylation of PARP1 itself, as well as other acceptor proteins, such as histones and topoisomerases. This modification potentially stimulates the recruitment and activity of other components of DNA repair pathways [1]. In its absence, DNA SSBs accumulate and degenerate to DNA double-strand breaks (DSBs), which are not appropriately repaired if the BRCA pathway is deficient or dysfunctional. This is thought to explain the exquisite sensitivity to PARP inhibitors of tumors with BRCA inactivation, a concept called "synthetic lethality" $[2,3]$. Recent clinical evidence confirmed that PARP inhibition is a promising therapeutic strategy either as single-agent in BRCA1 or BRCA2-mutated breast cancers [4], or in combination with cytotoxic chemotherapy in triple-negative (TN) breast cancers, a subgroup that shares many features with BRCA1-mutated tumors [5]. Several PARP inhibitors are currently in clinical development. However, until now, PARP1 mRNA expression has not been described in breast cancer. A few and relatively small (less than 95 samples) studies have been reported in melanoma [6, 7], ovarian cancer [8] and colon cancer [9], and showed frequent PARP1 overexpression, associated with poor-prognosis histo-clinical features. 
Here, we explored our gene expression database of 326 breast cancer samples profiled using oligonucleotide microarrays. Data were then combined with 12 publicly available expression datasets, resulting in a total of 2,485 invasive breast cancers informative for meta-analysis. Our primary objective was to describe the molecular epidemiology of this novel therapeutic target in a large population of early breast cancer patients. Secondary objectives included correlation between PARP1 expression and other clinical, pathological and molecular features, including survival.

\section{Patients and Methods}

\section{Gene expression data of breast cancer}

To determine PARP1 mRNA expression in breast cancer, we analyzed gene expression data of 326 breast tumor samples that we had profiled using oligonucleotide microarrays. Tumor tissues had been collected from 326 patients with invasive adenocarcinoma who underwent initial surgery at the Institut PaoliCalmettes (Marseilles, France) between 1987 and 2007. Each patient gave written informed consent and the study was approved by our institutional review board. Samples were macrodissected and frozen in liquid nitrogen within 30 min of removal. All specimens contained $>60 \%$ of tumor cells (as assessed before RNA extraction using frozen sections adjacent to the profiled samples). After surgery, patients were treated using a multimodal approach according to standard guidelines. DNA and RNA were extracted from frozen samples by using guanidium isothiocynanate and cesium chloride gradient as described previously [10]. RNA integrity was controlled on Agilent Bioanalyzer (Agilent Technologies). We had also profiled 11 normal breast 
(NB) tissue samples pooled in 4 RNA samples. Expression profiles had been established for these 326 cancers and 4 NB pools with Affymetrix U133 Plus 2.0 human oligonucleotide microarrays as previously described [11]. Scanning was done with Affymetrix GeneArray scanner and quantification with Affymetrix GeneChip Operating Software. Data were analyzed by the Robust Multichip Average method [12] in $\mathrm{R}$ using Bioconductor and associated packages. PARP1 expression was measured by analyzing the sole probe set present on our Affymetrix microarrays, ID 208644_at. Before analysis, gene expression levels for each tumor sample were centered by the average expression levels of the four NB samples. All data were then $\log 2$ transformed for display and analysis.

To examine the correlation between PARP1 mRNA expression and histoclinical features of tumors in a large series of samples, we analyzed 12 publicly available datasets collected from the National Center for Biotechnology Information (NCBI)/ Genbank GEO database (series entry GSE2034, GSE2990, GSE4922, GSE1456, GSE7390, GSE2741, GSE1992, GSE2740, GSE2607, GSE6130, GSE3165, GSE6128, GSE10886) or at the following web addresses http://bioinformatics.mdanderson.org/pubdata.html; http://microarray-

pubs.stanford.edu/wound NKI/; http://www.rii.com/publications/2002/vantveer.html. To be comparable across datasets and to exclude bias from population heterogeneity, PARP1 expression levels were standardized within datasets using the luminal A population as reference. Combined with our IPC series, this resulted in a total of 2,485 invasive breast cancers with PARP1 expression and histo-clinical data available for meta-analysis (Table 1).

The molecular subtypes related to the Stanford intrinsic breast cancer classification were determined using Single Sample Predictor (SSP) classifier based 
on a list of 306 intrinsic genes [13]. Briefly, after having identified the genes common between the intrinsic gene set and each expression dataset, we then used Distance Weighted Discrimination (DWD) [14] to normalize each dataset in order to be comparable to the 315 samples of the Hu's combined test sample set. Next, we defined the expression centroid of each subtype for the common probe sets in this combined test sample set [13]. Finally, we measured the correlation of each sample with each centroid. The sample was attributed the subtype corresponding to the most correlated centroid.

\section{Array-comparative genomic hybridization data of breast cancer}

Our analysis included data of genomic imbalances of 260 out of the 326 breast tumors. Data had been generated by array-comparative genomic hybridization (aCGH) using 244K CGH Microarrays (Hu-244A, Agilent Technologies) following a described protocol [10]. A pool of 13 normal male DNA had been used as reference. Scanning was done with Agilent Autofocus Dynamic Scanner (G2565BA, Agilent Technologies). Data analysis was done as described [10]. Extraction of data (log2 ratio) was done from CGH Analytics, whereas normalized and filtered log2 ratio was obtained from "Feature Extraction" software (Agilent Technologies). The PARP1 locus at 1q41 was analyzed and copy number changes were characterized as reported previously [10]. Eight probes matched the PARP1 gene on our Agilent chips. A tumor was considered as harboring a gain for PARP1 if at least 5 (out of 8 ) consecutive probes displayed a log2 ratio tumor/normal $>|0.5|$.

\section{Statistical analyses}


Study is retrospective and multicentric based on a large public data set. Comparisons of mean PARP1 expression level according to classical histo-clinical factors were done using Student t-test (2 variables) or one-way analysis of variance (ANOVA; more than 2 variables). Metastasis-free survival (MFS) was calculated from the date of diagnosis until date of distant relapse and follow-up was measured from the date of diagnosis to the date of last news for patients without relapse. Overall survival (OS) was calculated from the date of diagnosis until date of death and followup was measured from the date of diagnosis to the date of last news for patients without death. Survival curves were generated using Kaplan-Meier method and compared with the log-rank test. Univariate and multivariate analyses were done using Cox regression analysis. Variables tested in univariate analysis included patients'age at time of diagnosis ( $\leq 50$ years $v s>50$ ), pathological axillary lymph node status ( $\mathrm{pN}$ : negative vs positive), pathological tumor size (pT: pT1 vs pT2-4), pathological grade (I vs 2-3), immunohistochemical (IHC) estrogen receptor (ER), progesterone receptor (PR), and ERBB2 status (negative vs positive), and PARP1 mRNA expression (continuous value). Variables with a p-value $<0.10$ in univariate analysis were tested in multivariate analysis. All statistical tests were two sided at the $5 \%$ level of significance. Statistical analysis was done using the survival package (version 2.30) in the $\mathrm{R}$ software (version 2.4.1; http://www.cran.r-project.org/). We followed the reporting recommendations for tumour marker prognostic studies (REMARK) [15].

\section{Results}




\section{PARP1 mRNA expression and DNA copy number: IPC series}

We analyzed expression data generated using Affymetrix microarrays from 330 samples including 326 pre-treatment primary breast cancers and 4 NB samples collected at our institution. First, we observed that PARP1 mRNA expression was highly heterogeneous, with expression level varying across a large dynamic range and encompassing almost four base 2 logs. To address the impact of potential intratumor heterogeneity in this pattern, we took advantage of recently published microarray data generated from a series of 18 breast cancer samples [16]. In this study, gene expression profiles obtained from 2 to 3 biopsy replicates of the same tumor sample were available for comparison; we observed an intra-patient PARP1 mRNA expression variance significantly lower than inter-patient variance $(p=9.19 \mathrm{E}$ 29, ANOVA), suggesting that intra-tumor heterogeneity has a minor influence on the heterogeneous expression of PARP1 we have observed.

Whole-genome hierarchical clustering showed that PARP1 was located within a proliferation gene cluster, including for example MKI67 and PCNA, along with other genes involved in DNA damage repair such as RAD51 and ERCC4. Of note, PARP1 expression did not correlate with $B R C A 1$ and $B R C A 2$ expression (data not shown).

Compared to NB, PARP1 was overexpressed ( $\geq 2$-fold increase) in $58 \%$ of cancer samples (Figure 1a). Array-comparative genomic hybridization (aCGH) data, simultaneously available for 260 of the 326 samples, allowed us to analyze the PARP1 locus at 1q41. Amplification of the 1q41-q44 region is a frequent genetic alteration in breast cancer [17-19]. A significant genomic gain $(\log 2$ ratio $>|0.5|)$ or amplification (log2 ratio>|1|) was observed in 91 out of 260 (35\%) samples (the mean percent of probes displaying this copy number alteration was $99.2 \%[95 \mathrm{Cl}, 97.8-$ 100] within the 91 altered tumors). Moreover, a significant association between 
PARP1 mRNA expression and gene copies was observed: the mean expression level of PARP1 mRNA was more than twice higher in tumors with PARP1 gain or amplification compared with tumors displaying a normal gene copy number $(p<1$.E-8, t-test; Figure 1b). However, gain/amplification was not the sole mechanism of overexpression, which was also found in tumors without any gene copy number gain.

\section{PARP1 mRNA expression and histo-clinical correlations: meta-analysis}

Meta-analysis examined correlations between PARP1 mRNA expression and histo-clinical features of tumors in a dataset of 2,485 invasive breast cancer samples, including our series and 12 public microarray datasets. As shown in Table 2, PARP1 expression was significantly (t-test) associated with immunohistochemical (IHC) negativity for estrogen receptor (ER), progesterone receptor (PR) and ERBB2, with high grade, histological type (being the highest in medullary cancers and the lowest in lobular tumors), high pathological tumor size, with a trend for axillary lymph node involvement $(p=0.067)$, but not with age. For 430 cases with available IHC information, PARP1 expression was higher in TN samples (negative for ER, PR and ERBB2), compared to ERBB2+ (positive for ERBB2, whatever the ER and PR status) and ERBB2-/HR+ (positive for ER and/or PR, negative for ERBB2) samples ( $p=0.05$, one-way ANOVA, data not shown).

We looked for PARP1 expression in the transcriptional molecular subtypes defined by the intrinsic gene set [13]. PARP1 was overexpressed in basal samples compared to other subtypes (Figure 2). Interestingly, PARP1 expression was much more tightly associated with the basal subtype than with the TN subgroup. Indeed, among the 430 above-described cases with available IHC classification, the correlation of PARP1 mRNA with the molecular subtypes (basal, ERBB2, and others) 
was high ( $p=4.6 \mathrm{E}-6$, one-way ANOVA) and greatly superior to that observed with the IHC classification (data not shown). Examining the sole IPC dataset (where simultaneous mRNA and genomic data were available), it was possible to address within each molecular subtype the above-described association between PARP1 expression and gene copy gain. The association was significant (t-test) in basal $(p=5.06 \mathrm{E}-4)$, ERBB2 $(p=7.2 \mathrm{E}-3)$ and luminal $\mathrm{B}(p=6.28 \mathrm{E}-3)$ samples, but not in luminal $A$ and normal samples. PARP1 was overexpressed in 84,100 and $79 \%$ of PARP1-amplified/gained basal, ERBB2 and luminal B samples, respectively, versus 61 and $50 \%$ of luminal $A$ and normal samples, respectively.

Finally, we examined the prognostic impact of PARP1 expression, along with other known clinical or pathological factors. We first examined MFS. In this series, follow-up was available for 1,637 patients: 494 women developed metastatic relapse with a median time to relapse of 32 months, and 1,143 remained relapse-free with a median follow-up of 96 months. In univariate analysis, PARP1 expression (together with $\mathrm{pN}, \mathrm{pT}$, grade, and ER, PR, and ERBB2 IHC status) was associated with a worse MFS ( $\mathrm{HR}=1.12$ [1.04-1.22]; $p=0.004$; Figure 3a). However, this was not maintained in multivariate analysis (data not shown). Since potential prognostic factors for MFS may interact with and thus be confounded by systemic adjuvant therapies, we re-analyzed data according to the treatment received, adjuvant chemotherapy and/or hormonal therapy, no patient being exposed to adjuvant trastuzumab. There were 261 patients who had not received any adjuvant systemic therapy (subgroup CTOHTO). Among them, 91 developed metastatic relapse with a median time to relapse of 27 months, and 170 remained relapse-free with a median follow-up of 99 months. There were 602 patients who had not received any adjuvant chemotherapy, with or without hormonal therapy (subgroup CTOHT+/-), including 210 
who experienced metastatic relapse with a median time of 28 months, and 392 who did not relapse with a median follow-up of 100 months. As shown in Table 3 and Figure 3a, PARP1 mRNA expression was associated with a worse MFS in univariate analysis in both subgroups $(\mathrm{HR}=1.25$ [1.04-1.51], $p=0.017$ in subgroup CTOHTO, and $\mathrm{HR}=1.12$ [0.994-1.27], $p=0.063$ in subgroup $\mathrm{CTOHT+/-).} \mathrm{In} \mathrm{both} \mathrm{subgroups,} \mathrm{PARP1}$ expression remained an independent prognostic factor for MFS in multivariate analysis $(\mathrm{HR}=1.24$ [1-1.53], $p=0.054$ in subgroup $\mathrm{CTOHTO}$, and $\mathrm{HR}=1.24$ [1.02-1.51], $p=0.035$ in $\mathrm{CTOHT}+/$. By contrast, in 334 patients identified as having received adjuvant chemotherapy (103 with metastatic relapse with a median time to relapse of 27 months, and 231 without any metastatic relapse with a median follow-up of 71 months), no correlation existed between PARP1 expression and MFS (HR=1.03 [0.87-1.22], $p=0.72$; Figure 3a).

Regarding OS, follow-up was available for 1,115 patients: 285 women died with a median time of 49 months and 830 were alive with a median follow-up of 100 months. In univariate analysis, PARP1 expression was associated with a worse OS $(H R=1.16$ [1.04-1.29]; $p=0.006$; Figure $3 b)$. However, this was not maintained in multivariate analysis (data not shown). In the CTOHTO subgroup (163 patients with available follow-up), 43 patients died with a median time of 46 months and 120 were alive with a median follow-up of 108 months. In the CTOHT+/- subgroup, 213 patients had follow-up data available, including 53 who died with a median time of 47 months and 160 alive with a median follow-up of 101 months. In the CT1 subgroup (326 patients with available follow-up), 93 patients died with a median time to death of 41 months and 233 were alive with a median follow-up of 74 months. No significant association was found between PARP1 expression and OS in any subgroup $(\mathrm{HR}=1.23$ [0.93-1.62], $p=0.15$ in CTOHT0; $\mathrm{HR}=1.18$ [0.92-1.52], $p=0.2$ in CTOHT+/-; 
$\mathrm{HR}=1.13$ [0.94-1.36], $p=0.18$ in CT1), even though trends similar to MFS (lower survival in high PARP1-expressing tumors in untreated patients only) were observed (Figure 3b).

\section{Discussion}

To date PARP1 mRNA expression and DNA copy number alterations have not been described in breast cancer. In this large series, we show that PARP1 expression is heterogeneous, with overexpression found in a significant number of breast cancers, in part due to genomic gain/amplification. This is particularly true in TN and even more in basal samples, and to a lesser degree in ERBB2+ and luminal samples. However, the role of such an overexpression in tumor initiation or progression, if any, remains to be elucidated. In addition, and for the first time to our knowledge, we have shown a significant and independent association between PARP1 expression and metastasis-free survival in breast cancer. Importantly, this association was restricted to patients not treated with any adjuvant chemotherapy.

Exploiting DNA repair alterations using PARP inhibition $[4,5]$ was recently shown as a promising approach in BRCA-mutated or TN breast cancers, which are classically associated with the basal subtype [20]. Thus, in a phase I dose-escalation study, Fong and colleagues selected a population enriched in BRCA-associated cancers [4]. In the overall population, there was no objective response. In the group of 19 patients with a documented BRCA mutation, including breast, ovarian, and prostate malignancies, there was a $47 \%$ response rate and a $63 \%$ clinical benefit rate. In TN breast cancer, a randomized phase II study compared addition of a 
PARP1 inhibitor, BSI-201, to chemotherapy with gemcitabine and carboplatin versus chemotherapy alone [5]. Preliminary data demonstrated that the addition of BSI-201 was associated with highly significant improvements in response (from $16 \%$ to $48 \%$ ), in progression-free survival (median from 3.3 to 6.9 months), as well as overall survival. A randomized phase III study is currently underway to confirm these results with gemcitabine, carboplatin, and BSI-201. Moreover, cisplatin-based neoadjuvant treatment [21] provided dramatic pathological response rate (nearly $75 \%$ ) in a smallsized population of tumors occurring in BRCA-mutated patients. In addition, cisplatin as single-agent induced a promising response rate of $22 \%$ in TN breast cancer, which was correlated with low BRCA expression [22]. These convergent clinical data suggest that tumors with deficient DNA-repair phenotypes, thought to be enriched in BRCA-mutated and TN subtypes, could be very sensitive to PARP inhibitors and DNA-damaging agents, alone or in combination. However, reliable and robust biomarkers that allow the accurate identification of alterations in functional DNA repair pathways (the so-called "BRCAness" phenotype, with the highest probability to benefit from these therapies) are still lacking. It still remains to be demonstrated whether the major increase in PARP1 expression observed in our study in some breast cancers might be such a marker. Speculatively, it could reflect a regulatory response to genetic instability, aiming to compensate for an abnormal rate of DNA damages, explaining why this event is more pregnant in the most instable subtypes, such as TN and basal. In this regard, our observation that the prognostic value of PARP1 expression was lost in patients receiving adjuvant chemotherapy could suggest that overexpression of PARP1 may be associated with tumor sensitivity to cytotoxic treatment, essentially cyclophosphamide and/or anthracycline-based in our retrospective series. Such an hypothesis is consistent with the recently reported 
positive correlation between PARP1 protein expression and response to neoadjuvant chemotherapy [23, 24]. In this study, 646 breast cancer samples from the GeparTrio neoadjuvant phase III trial were centrally stained by IHC for PARP protein. Similarly to what we observed at the mRNA level, PARP protein was found in all molecular subtypes, more frequently in ERBB2-positive and TN tumors, and correlated with most known prognostic factors, including poor differentiation, non-lobular histological type and negative hormonal receptivity. Notably, PARP expression independently predicted for the pathological complete response $(\mathrm{pCR})$ to neoadjuvant taxaneanthracycline-based chemotherapy: patients with high expression showed a pCR rate of $25.7 \%$ compared to $18.8 \%$ and $6.1 \%$ in patients with medium or low expression $(p<0.001)$. Interestingly, it is worth emphasizing that the deficient DNA-repair phenotype may be observed beyond these subtypes. For example, recent data have suggested that PTEN deficiency may associate with reduction in RAD51 expression and perturbation of homologous recombination in BRCA-intact human cancer cells, leading to high sensitivity to PARP inhibition [25]. Moreover, a similar deficiency in DSBs repair may be functionally induced in various non-genetic conditions, including hypoxia or even PARP inhibition itself, both setting being associated with a repression in $B R C A 1$ and $R A D 51$ transcription and therefore an increased efficiency of anti-PARP treatment [26]. Altogether, these data support the hypothesis that PARP inhibition may have broader applications in breast cancer treatment than anticipated based on initial preclinical and clinical results.

In conclusion, we report the first large-scale integrated analysis of PARP1 expression and genomic status in breast cancer. Whether PARP1 overexpression may identify breast cancers with higher probability of response to PARP inhibitors or DNA-damaging agents needs to be determined. But, if this hypothesis were 
confirmed, our data should not only strengthen the interest for these compounds in basal breast cancers, but also suggest promising applications in a larger fraction of patients, beyond the basal subtype.

\section{Conflict of interest}

All authors declare that they have no conflict of interest to disclose

\section{Aknowledgments}

Our work is supported by Institut Paoli-Calmettes, Inserm, Institut National du Cancer (Tr 2008), Association pour le Recherche contre le Cancer, Ligue Nationale contre le Cancer (label DB), Ligue contre le Cancer (comité Corse du Sud), and Fondation pour la Recherche Médicale (RS 2009). 


\section{References}

1. Ame JC, Spenlehauer C, de Murcia G (2004) The PARP superfamily. Bioessays 26:882-893.

2. Farmer H, McCabe N, Lord CJ, Tutt ANJ, Johnson DA, Richardson TB, Santarosa M, Dillon KJ, Hickson I, Knights C et al (2005) Targeting the DNA repair defect in BRCA mutant cells as a therapeutic strategy. Nature 434:917921.

3. Bryant HE, Schultz N, Thomas HD, Parker KM, Flower D, Lopez E, Kyle S, Meuth M, Curtin NJ, Helleday T (2005) Specific killing of BRCA2-deficient tumours with inhibitors of poly(ADP-ribose) polymerase. Nature 434:913-917.

4. Fong PC, Boss DS, Yap TA, Tutt A, Wu P, Mergui-Roelvink M, Mortimer P, Swaisland H, Lau A, O'Connor MJ et al (2009) Inhibition of Poly(ADP-Ribose) Polymerase in Tumors from BRCA Mutation Carriers. N Engl J Med 361:123134.

5. O'Shaughnessy J, Osborne C, Pippen J, Yoffe M, Patt D, Monaghan G, Rocha C, Ossovskaya V, Sherman B, Bradley C (2009) Efficacy of BSI-201, a poly (ADP-ribose) polymerase-1 (PARP1) inhibitor, in combination with gemcitabine/carboplatin $(G / C)$ in patients with metastatic triple-negative breast cancer (TNBC): Results of a randomized phase II trial. J Clin Oncol (Meeting Abstracts) 27:3.

6. Csete B, Lengyel Z, Kadar Z, Battyani Z (2009) Poly(adenosine diphosphateribose) polymerase-1 expression in cutaneous malignant melanomas as a new molecular marker of aggressive tumor. Pathol Oncol Res 15:47-53.

7. Staibano S, Pepe S, Lo Muzio L, Somma P, Mascolo M, Argenziano G, Scalvenzi M, Salvatore G, Fabbrocini G, Molea G et al (2005) Poly(adenosine diphosphate-ribose) polymerase 1 expression in malignant melanomas from photoexposed areas of the head and neck region. Hum Pathol 36:724-731.

8. Brustmann H (2007) Poly(adenosine diphosphate-ribose) polymerase expression in serous ovarian carcinoma: correlation with p53, MIB-1, and outcome. Int J Gynecol Pathol 26:147-153.

9. Nosho K, Yamamoto H, Mikami M, Taniguchi H, Takahashi T, Adachi $\mathrm{Y}$, Imamura A, Imai K, Shinomura Y (2006) Overexpression of poly(ADP-ribose) 
polymerase-1 (PARP-1) in the early stage of colorectal carcinogenesis. Eur $\mathrm{J}$ Cancer 42:2374-2381.

10. Adelaide J, Finetti P, Bekhouche I, Repellini L, Geneix J, Sircoulomb F, Charafe-Jauffret E, Cervera N, Desplans J, Parzy D et al (2007) Integrated profiling of basal and luminal breast cancers. Cancer Res 67:11565-11575.

11. Bertucci F, Finetti P, Cervera N, Charafe-Jauffret E, Mamessier E, Adelaide J, Debono S, Houvenaeghel G, Maraninchi D, Viens P et al (2006) Gene expression profiling shows medullary breast cancer is a subgroup of basal breast cancers. Cancer Res 66:4636-4644.

12. Irizarry RA, Hobbs B, Collin F, Beazer-Barclay YD, Antonellis KJ, Scherf U, Speed TP (2003) Exploration, normalization, and summaries of high density oligonucleotide array probe level data. Biostatistics 4:249-264.

13. Hu Z, Fan C, Oh D, Marron JS, He X, Qaqish B, Livasy C, Carey L, Reynolds $E$, Dressler $L$ et al (2006) The molecular portraits of breast tumors are conserved across microarray platforms. BMC Genomics 7:96.

14. Benito M, Parker J, Du Q, Wu J, Xiang D, Perou CM, Marron JS (2004) Adjustment of systematic microarray data biases. Bioinformatics 20:105-114.

15. McShane LM, Altman DG, Sauerbrei W, Taube SE, Gion M, Clark GM (2006) REporting recommendations for tumor MARKer prognostic studies (REMARK). Breast Cancer Res Treat 100:229-235.

16. Barry WT, Kernagis DN, Dressman HK, Griffis RJ, Hunter JD, Olson JA, Marks JR, Ginsburg GS, Marcom PK, Nevins JR et al (2010) Intratumor heterogeneity and precision of microarray-based predictors of breast cancer biology and clinical outcome. J Clin Oncol 28:2198-2206.

17. Bieche I, Champeme MH, Lidereau R (1995) Loss and gain of distinct regions of chromosome 1q in primary breast cancer. Clin Cancer Res 1:123-127.

18. Knuutila S, Autio K, Aalto $Y$ (2000) Online access to CGH data of DNA sequence copy number changes. Am J Pathol 157:689.

19. Larramendy ML, Lushnikova T, Bjorkqvist AM, Wistuba, II, Virmani AK, Shivapurkar N, Gazdar AF, Knuutila S (2000) Comparative genomic hybridization reveals complex genetic changes in primary breast cancer tumors and their cell lines. Cancer Genet Cytogenet 119:132-138.

20. Cleator S, Heller W, Coombes RC (2007) Triple-negative breast cancer: therapeutic options. Lancet Oncol 8:235-244. 
21. Byrski T, Gronwald J, Huzarski T, Grzybowska E, Budryk M, Stawicka M, Mierzwa T, Szwiec M, Wisniowski R, Siolek M et al (2010) Pathologic complete response rates in young women with BRCA1-positive breast cancers after neoadjuvant chemotherapy. J Clin Oncol 28:375-379.

22. Silver DP, Richardson AL, Eklund AC, Wang ZC, Szallasi Z, Li Q, Juul N, Leong C-O, Calogrias D, Buraimoh A et al (2009) Efficacy of Neoadjuvant Cisplatin in Triple-Negative Breast Cancer. J Clin Oncol:JCO.2009.2022.4725.

23. von Minckwitz G, Müller B, Loibl S, Blohmer JU, duBois A, Huober J, Kandolf R, Budczies J, Denkert C 443 PARP is expressed in all subtypes of early breast cancer and is a predictive factor for response to neoadjuvant chemotherapy. European Journal of Cancer Supplements 8:188-188.

24. Loibl S, Mueller B, Von Minckwitz G, Blohmer JU, Bois Ad, Huober JB, Fend $F$, Budczies J, Denkert C PARP expression in early breast cancer and its predictive value for response to neoadjuvant chemotherapy. J Clin Oncol (Meeting Abstracts) 28:10511-.

25. Mendes-Pereira AM, Martin SA, Brough R, McCarthy A, R. Taylor J, Kim J-S, Waldman T, Lord CJ, Ashworth A (2009) Synthetic lethal targeting of PTEN mutant cells with PARP inhibitors. EMBO Molecular Medicine 1:315-322.

26. Hegan DC, Lu Y, Stachelek GC, Crosby ME, Bindra RS, Glazer PM (2010) Inhibition of poly(ADP-ribose) polymerase down-regulates BRCA1 and RAD51 in a pathway mediated by E2F4 and p130. Proceedings of the National Academy of Sciences 107:2201-2206. 
Table 1: Histo-clinical characteristics of the 2,485 breast cancer patients.

\begin{tabular}{|c|c|}
\hline Variables and categories & $\mathbf{N}(\%)$ \\
\hline & \\
\hline $\begin{array}{l}\text { Female } \\
\text { Age (years) }\end{array}$ & 2485 (100\%) \\
\hline$\leq 50$ & $897(51 \%)$ \\
\hline$>50$ & $856(49 \%)$ \\
\hline Histological type & \\
\hline DUC & 495 (79\%) \\
\hline LOB & $35(6 \%)$ \\
\hline MIX & $30(5 \%)$ \\
\hline MED & $24(4 \%)$ \\
\hline TUB & $6(1 \%)$ \\
\hline MUC & $5(1 \%)$ \\
\hline Other & $32(5 \%)$ \\
\hline $\begin{array}{l}\text { Pathological axillary lymph node invasion } \\
\text { (pN) }\end{array}$ & \\
\hline No & $1280(66 \%)$ \\
\hline $\begin{array}{l}\text { Yes } \\
\text { Pathological tumour size (nT) }\end{array}$ & $671(34 \%)$ \\
\hline $\begin{array}{l}\text { Pathological tumour size (pT) } \\
\text { pT1 }\end{array}$ & $753(40 \%)$ \\
\hline pT2 & $877(47 \%)$ \\
\hline рT3 & $169(9 \%)$ \\
\hline pT4 & $65(3 \%)$ \\
\hline Grade & \\
\hline 1 & $337(16 \%)$ \\
\hline 2 & $820(39 \%)$ \\
\hline 3 & $932(45 \%)$ \\
\hline ER (IHC) & \\
\hline Negative & $653(32 \%)$ \\
\hline Positive & $1362(68 \%)$ \\
\hline $\mathrm{PR}(\mathrm{IHC})$ & \\
\hline Negative & 306 (42\%) \\
\hline Positive & $418(58 \%)$ \\
\hline ERBB2 (IHC) & \\
\hline Negative & $334(78 \%)$ \\
\hline Positive & $96(22 \%)$ \\
\hline Adjuvant chemotherapy & \\
\hline No & $625(57 \%)$ \\
\hline Yes & $480(43 \%)$ \\
\hline Chemotherapy regimen & \\
\hline $\mathrm{CMF}$ & $10(2 \%)$ \\
\hline AC & $195(40 \%)$ \\
\hline AC-T & $165(34 \%)$ \\
\hline Unknown & $110(24 \%)$ \\
\hline Adjuvant hormonal therapy & \\
\hline No & $815(76 \%)$ \\
\hline Yes & 254 (24\%) \\
\hline Follow-up (months) & \\
\hline Median & 96 \\
\hline Metastatic relapse & \\
\hline No & $1143(70 \%)$ \\
\hline Yes & $494(30 \%)$ \\
\hline
\end{tabular}


$\mathrm{DUC}=$ ductal; $\mathrm{LOB}=$ lobular; $\mathrm{MED}=$ medullary; $\mathrm{MIX}=$ mixed;

MUC = mucinous; TUB = tubular; $\mathrm{CMF}=$ cyclophosphamide, methotrexate, 5 Fluorouracile regimen; $A C=$ anthracycline, cyclophosphamide regimen; AC- $\mathrm{T}=$ anthracycline, cyclophosphamide, taxane regimen. 
Table 2: PARP1 mRNA expression according to histo-clinical features in 2,485 breast cancer samples.

\begin{tabular}{|c|c|c|}
\hline $\begin{array}{c}\text { Variables and categories } \\
(\mathrm{N})\end{array}$ & $\begin{array}{l}\text { Mean PARP1 mRNA } \\
\text { expression (log2) }\end{array}$ & $p$-value \\
\hline Age (years) & & 0.44 \\
\hline$\leq 50(897)$ & 1.08 & \\
\hline$>50(856)$ & 1.12 & \\
\hline Histological type & & 4.49E-9 \\
\hline DUC (495) & 1.15 & \\
\hline LOB (35) & 0.85 & \\
\hline MED (24) & 2.61 & \\
\hline $\operatorname{MIX}(30)$ & 0.77 & \\
\hline MUC (5) & 0.96 & \\
\hline TUB (6) & 0.95 & \\
\hline Other (32) & 1.37 & \\
\hline Pathological axillary lymph node invasion & & 0.067 \\
\hline$(\mathrm{pN})$ & 1.08 & \\
\hline $\begin{array}{l}\text { no }(1280) \\
\text { yes }(671)\end{array}$ & 1.18 & \\
\hline Pathological tumour size (pT) & & 0.0007 \\
\hline pT1 (753) & 0.98 & \\
\hline pT2 (877 & 1.16 & \\
\hline pT3 (169) & 1.30 & \\
\hline Grade $^{\text {pT4 (65) }}$ & 1.29 & $464 \mathrm{~F}-20$ \\
\hline $1(337)$ & 0.67 & \\
\hline $2(820)$ & 0.96 & \\
\hline $3(932)$ & 1.32 & \\
\hline $\mathrm{ER}(\mathrm{IHC})$ & & $7.27 \mathrm{E}-6$ \\
\hline positive $(653$ & 1.02 & \\
\hline $\begin{array}{l}\text { negative (1362) } \\
\text { PR (IHC) }\end{array}$ & 1.28 & 0010 \\
\hline $\begin{array}{l}\text { PR (IHC) } \\
\text { positive (306) }\end{array}$ & 1.04 & 0.018 \\
\hline negative (418) & 1.24 & \\
\hline ERBB2 (IHC) & & 0.05 \\
\hline positive (96) & 0.96 & \\
\hline
\end{tabular}


Table 3: Univariate and multivariate analyses in MFS in patients untreated with systemic adjuvant chemotherapy

\section{A/ Subgroup CTOHTO}

\begin{tabular}{lccc||ccc}
\hline & \multicolumn{3}{c|}{ Univariate } & \multicolumn{3}{c}{ Multivariate } \\
\hline Variables & $\mathbf{N}$ & HR [Cl95\%] & $\begin{array}{c}\boldsymbol{p} \text { - } \\
\text { value }\end{array}$ & $\mathbf{N}$ & HR [Cl95\%] & $\begin{array}{c}\boldsymbol{p} \text { - } \\
\text { value }\end{array}$ \\
\hline Age $>50$ & 261 & $0.81[0.49-1.31]$ & 0.38 & & & \\
ER $(\mathrm{IHC})$ pos & 259 & $0.58[0.38-0.89]$ & 0,012 & 133 & $0.69[0.4-1.19]$ & 0,18 \\
PR $(\mathrm{IHC})$ pos & 38 & $0.77[0.21-2.87]$ & 0,695 & & & \\
ERBB2 (IHC) pos & 34 & NA & NA & & & \\
pN pos & 134 & $2.88[1.66-5]$ & 0,0001 & 133 & $2.12[1.22-3.7]$ & 0,0078 \\
pT T2-4 & 260 & $2.07[1.37-3.13]$ & 0,0005 & 133 & $1.83[1.07-3.12]$ & 0,027 \\
Grade 2-3 & 259 & $4.15[2.01-8.59]$ & 0,0001 & 133 & $2.22[0.76-6.46]$ & 0,14 \\
mRNA PARP1 & 261 & $1.25[1.04-1.51]$ & 0,017 & 133 & $1.24[1-1.53]$ & 0,054 \\
\hline
\end{tabular}

B/ Subgroup CTOHT+/-

\begin{tabular}{|c|c|c|c|c|c|c|}
\hline \multirow[b]{2}{*}{ Variables } & \multicolumn{3}{|c|}{ Univariate } & \multicolumn{3}{|c|}{ Multivariate } \\
\hline & $\mathbf{N}$ & HR [Cl95\%] & $\begin{array}{c}p- \\
\text { value }\end{array}$ & $\mathbf{N}$ & HR [Cl95\%] & $\begin{array}{c}p- \\
\text { value }\end{array}$ \\
\hline Age $>50$ & 316 & $0.76[0.50-1.17]$ & 0.21 & & & \\
\hline ER $(\mathrm{IHC})$ pos & 600 & $0.72[0.54-0.97]$ & 0,029 & 166 & $0.6[0.36-0.98]$ & 0,042 \\
\hline PR (IHC) pos & 73 & $0.85[0.3-2.47]$ & 0,772 & & & \\
\hline ERBB2 $(\mathrm{IHC})$ pos & 65 & 0.00 [0.00-Inf] & 1 & & & \\
\hline pN pos & 456 & 2.5 [1.66-3.78] & $\begin{array}{c}1,35 \mathrm{E}- \\
05\end{array}$ & 166 & $2.34[1.42-3.84]$ & 0,0008 \\
\hline рT T2-4 & 314 & 2.18 [1.47-3.24] & 0,0001 & 166 & 1.59 [0.98-2.58] & 0,059 \\
\hline Grade 2-3 & 312 & $4.24[2.14-8.4]$ & $\begin{array}{c}3,54 \mathrm{E}- \\
05\end{array}$ & 166 & $1.99[0.83-4.76]$ & 0,12 \\
\hline mRNA PARP1 & 602 & $1.12[0.99-1.27]$ & 0,063 & 166 & $1.24[1.02-1.51]$ & 0,035 \\
\hline
\end{tabular}

NA, not applicable (no ERBB2-positive patient) 


\section{Legends of Figures}

Figure 1: mRNA expression of PARP1 in breast cancer.

a/ PARP1 expression across 326 breast cancer (BC) samples profiled using Affymetrix U133 Plus 2.0 human oligonucleotide microarrays. Expression levels in tumors are reported as a box plot relatively to expression in normal breast (NB, horizontal solid line). Median and ranges are indicated. Overexpression in tumors was defined as a ratio of expression tumor/NB $\geq 2$ (horizontal dashed line).

b/ Expression across $260 \mathrm{BC}$ samples profiled also by aCGH using $244 \mathrm{~K}$ CGH microarrays (Hu-244A, Agilent Technologies). Box plots of PARP1 expression in BC are shown according to PARP1 genomic status, with (left) and without (right) gain defined as a DNA copy number ratio tumor/NB $\geq 2$ (horizontal dashed line). Differences in PARP1 expression levels between both groups were tested for significance using Student t-test. For each box plot, median and ranges are indicated.

Figure 2: mRNA expression of PARP1 according to breast cancer molecular subtypes.

PARP1 expression across 2,485 breast cancer (BC) samples with publicly available data was examined according to molecular subtypes as defined in [13]. Box plots of PARP1 expression in $\mathrm{BC}$ are shown according to basal, ERBB2, luminal $\mathrm{A}$ and $\mathrm{B}$, and normal-like subtypes. Differences in PARP1 expression levels between the subtypes were tested for significance using one-way ANOVA. For each box plot, median and ranges are indicated. 
Figure 3: Metastasis-free and overall survivals according to PARP1 mRNA expression.

a/ Kaplan-Meier MFS curves in patients with high (ratio of expression tumor/NB $\geq 2$ ) and low (ratio of expression tumor/NB <2) expression of PARP1 mRNA: all patients (left), untreated patients (CTOHTO, middle), and patients treated with adjuvant chemotherapy (CT1, right).

b/ Kaplan-Meier OS curves (the legend is similar to a/). 


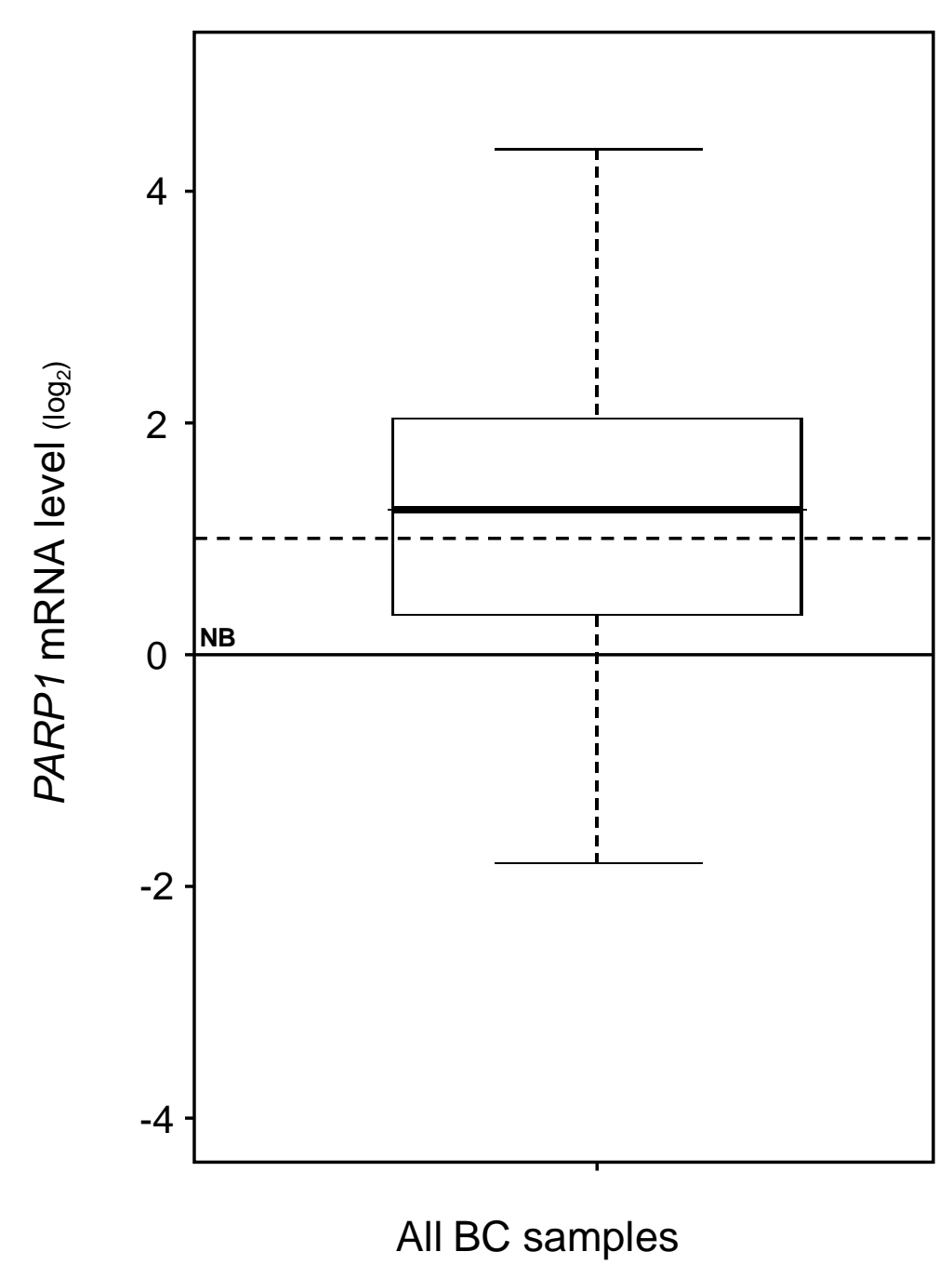

All BC samples

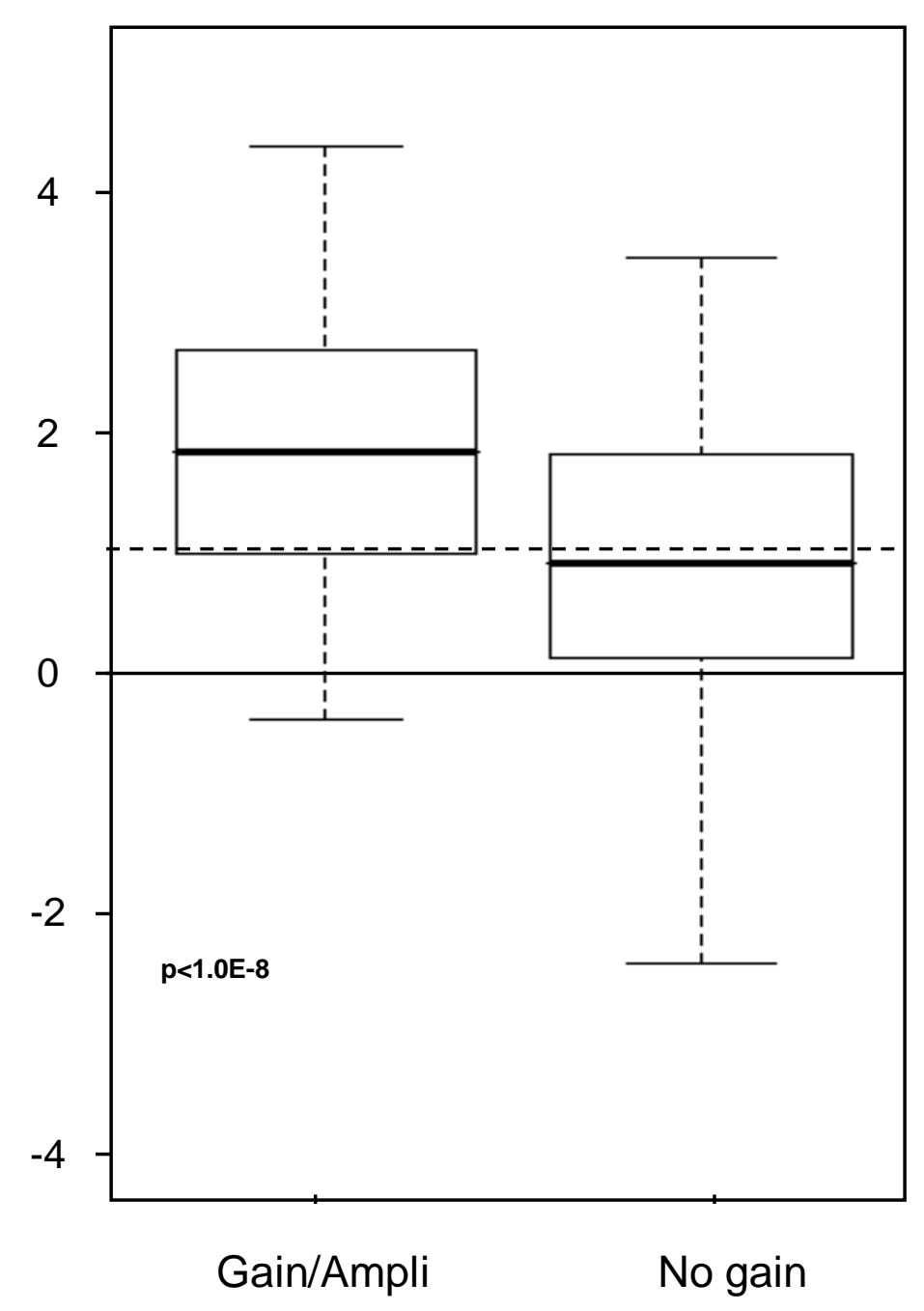

Gain/Amplì

No gain 


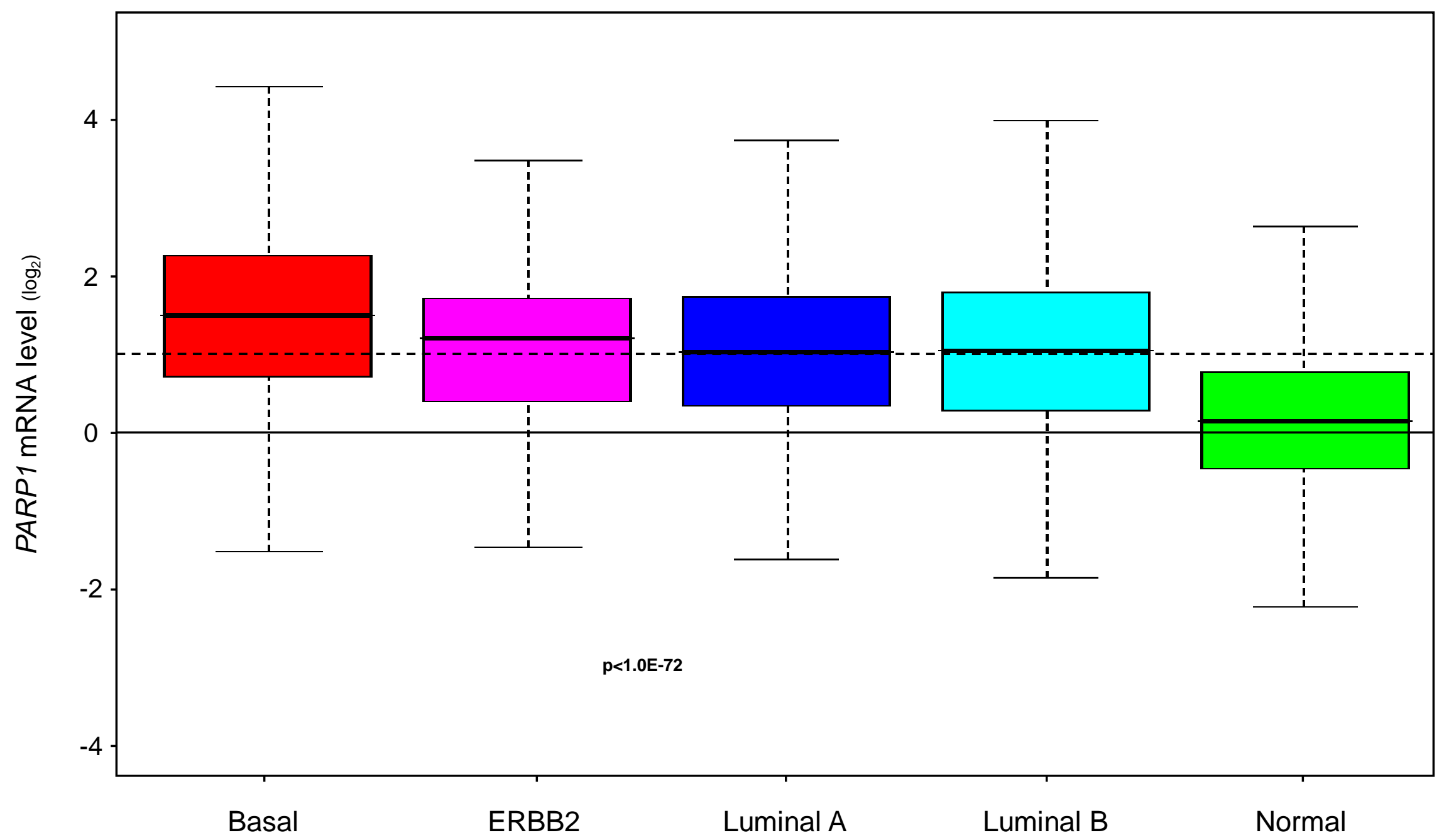


A
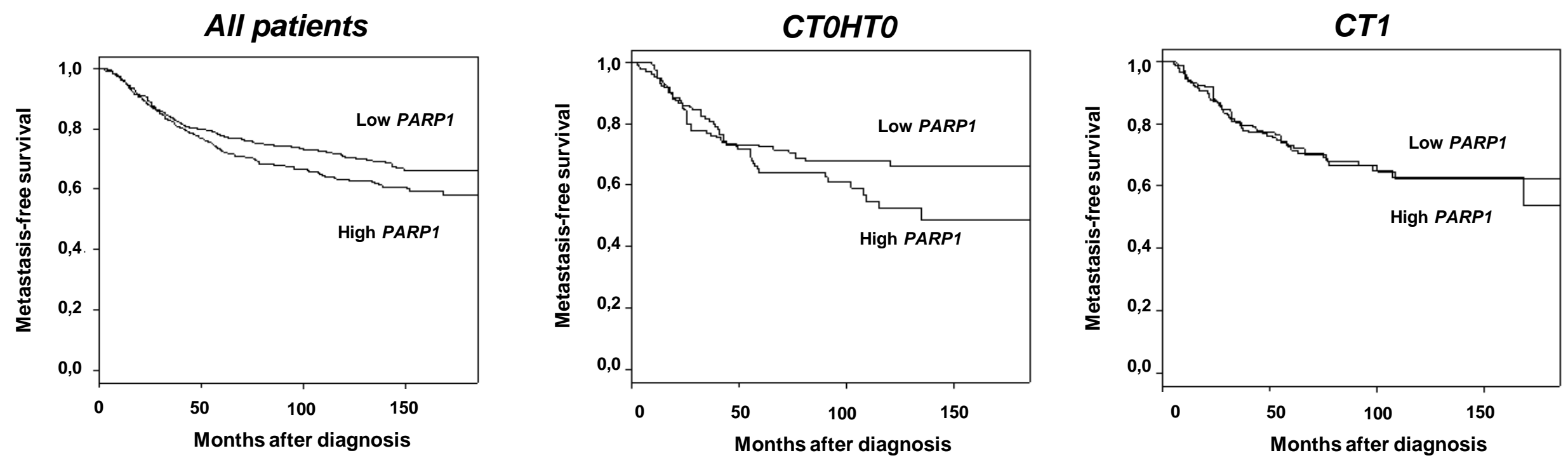

B
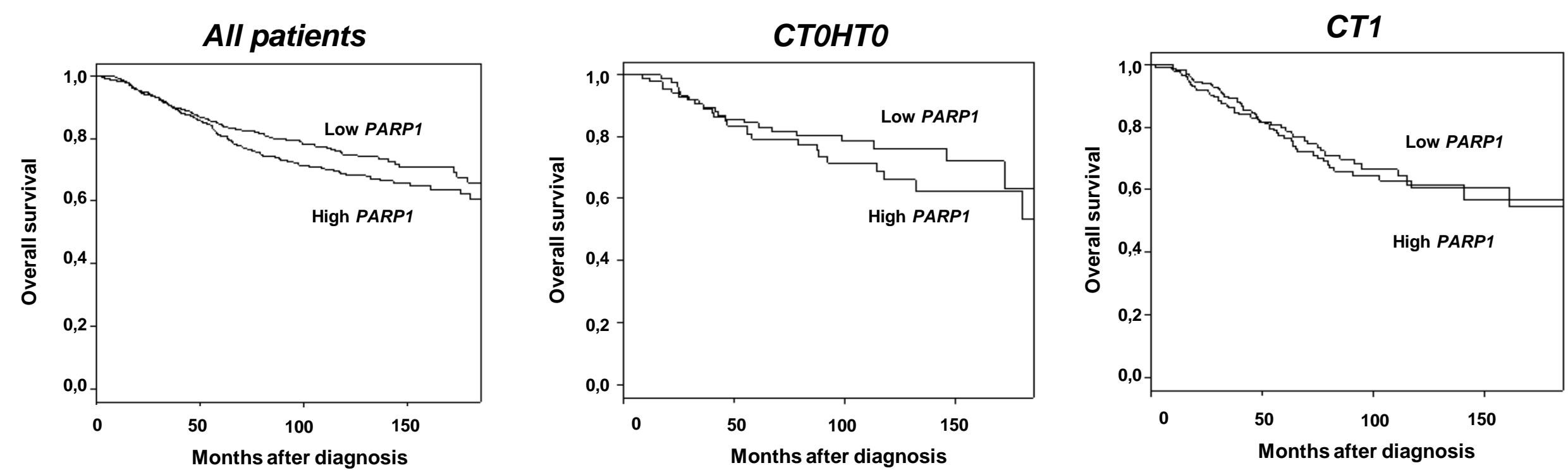